\title{
PROCEDIMENTO PARA LEGALIZAÇÃO E LICENCIAMENTO DE OBRAS RESIDENCIAIS MULTIFAMILIARES DO PROGRAMA MINHA CASA MINHA VIDA NA CIDADE DO RIO DE JANEIRO
}

\author{
Camila Estevão da Silva \\ Graduanda em Engenharia Civil no Centro Universitário Augusto Motta - UNISUAM. \\ camilaestevao.engcv@gmail.com \\ Rachel Cristina Santos Pires \\ Mestre em Desenvolvimento Local, Engenheira Civil e Professora Universitária \\ no Centro Universitário Augusto Motta - UNISUAM. \\ rachelpireseng@gmail.com
}

\section{RESUMO}

Diante do aumento da população no estado do Rio de janeiro, segundo estimativas divulgadas em agosto de 2017, pelo Instituto Brasileiro de Geografia e Estatística (IBGE), o Rio de Janeiro alcança a marca de mais de 6.520 milhões de habitantes, o 20 estado mais populoso do Brasil. Devido ao crescimento e a morosidade do sistema, tem sido observada a ocorrência de filas de espera para que os empreendimentos sejam aprovados, cujo tempo para aprovações dos projetos pode até ser superior ao de execução da obra, fato que chama a atenção e, para que não haja atraso na obra, esse prazo deve ser levado em consideração. $O$ objetivo deste trabalho de conclusão de curso é apresentar as normas urbanísticas no processo de aprovação de projetos, regras e modos operantes das instituições e empresas relacionadas ao procedimento de legalização, detalhando os mecanismos para auxiliar profissionais que tenham interesse em trabalhar nesta área, exemplificando especificamente a legalização de uma obra multifamiliar do Programa Minha Casa Minha Vida (PMCMV) no Rio de janeiro. As informações que constarão neste trabalho sobre os processos envolvidos em legalização e licenciamento de obras, foram pesquisadas nas respectivas organizações: Prefeitura Municipal do Rio de Janeiro e suas secretarias e Receita federal, todos amparados pelas leis Federais, Estaduais e Municipais vigentes no ano de 2018.

Palavras - Chave: Legalização, licenciamento, multifamiliar, habite-se, Rio de Janeiro.

\section{PROCEDURE FOR LEGALIZATION AND LICENSING OF MULTIFAMILIARY RESIDENTIAL WORKS OF THE MY HOUSE MY LIFE PROGRAM IN THE CITY OF RIO DE JANEIRO}

\begin{abstract}
According to estimates published in August 2017 by the Brazilian Institute of Geography and Statistics (IBGE), Rio de Janeiro reaches the mark of more than 6,520 million
\end{abstract}


inhabitants, the second most populous state in the state of Rio de Janeiro. population of Brazil. Due to the growth and slowness of the system, waiting queues have been observed for the projects to be approved, and the time for approvals of the projects may be higher than that of execution of the project. there is no delay in the work, this period should be taken into account. The objective of this work is to present urban norms in the process of approving projects, rules and operating modes of institutions and companies related to the legalization procedure, detailing the mechanisms to assist professionals who are interested in working in this area, specifically exemplifying the legalization of a multifamily work of the My Home My Life Program (PMCMV) in Rio de Janeiro. The information that will be included in this work on the processes involved in legalization and licensing of works was searched in the respective organizations: Rio de Janeiro City Hall and its secretaries and Federal Revenue, all of which are covered by Federal, State and Municipal laws in force in the year 2018.

Keywords: Legalization, licensing, multi-family, live, Rio de Janeiro

\section{INTRODUÇÃO}

No processo de elaboração e execução de construções em todo território nacional é necessário que se siga um processo de regulamentação junto aos órgãos competentes à construção civil, sejam eles técnicos, ambientais, jurídicos, e outros que se fazem necessários. Dentro da regulamentação existem diversos procedimentos a serem seguidos, desde a consulta a viabilidade, início do projeto, no decorrer da execução dele, até a sua conclusão, com todos os autos necessários para dar como concluído o projeto à disposição de todos os órgãos competentes com a vistoria e aprovação da obra segundo os padrões que cada um exige.

A motivação para a realização deste trabalho, está no fato de que a falta de informação por parte das construtoras e de profissionais em relação à legalização que precede o início da construção, gera várias idas e vindas em diversos órgãos públicos, até que chegue a compreensão do procedimento correto para se iniciar uma construção sem nenhuma pendência legal quanto à documentação. A disponibilização pelas entidades de informações simples, explicando o passo a passo para uma construção legal, assim como procedimentos menos burocráticos nos trâmites legais, certamente diminuiriam as filas e o tempo para a realização dos procedimentos de liberação do "Habite-se".

No presente artigo, será abordado sobre como legalizar e licenciar as edificações e grupamentos de edificações de empreendimentos de interesse social PMCMV, 
voltados à população de baixa renda salarial, incluídos em programas governamentais de habitação municipal, estadual e federal, seguindo as competências abrangentes da Lei Complementar no 40/90, regulamentada pelo Decreto no 19.828/01, que visa ampliar as condições favoráveis de moradias à população de baixa renda em áreas urbanas com infraestrutura básica de serviços públicos já existentes.

São considerados Empreendimentos Habitacionais de Interesse Social aqueles reconhecidos pela Secretaria Municipal de Habitação como inseridos na Política Habitacional Municipal, Estadual ou Federal, destinados a população com renda de até 10 salários-mínimos. Os processos são enquadrados pela $\mathrm{SMH}$, que atesta o atendimento a todos os requisitos necessários.

O público a ser atingido são as construtoras e os profissionais do ramo da engenharia civil que pretendem trabalhar com a demanda de aprovação de projetos incluídos no PMCMV na Cidade do Rio de Janeiro.

O processo a ser empregado é o estudo dos aspectos técnicos e legais envolvidos, levantamento de dados, apresentação de um fluxograma do processo de licenciamento, e planilha para acompanhamento das condicionantes da licença de obras e aceitação dos serviços pelos entes públicos envolvidos, visando otimizar o tempo total de legalização.

\section{REVISÃO BIBLIOGRÁFICA}

\subsection{Viabilidade técnica do projeto}

Segundo Madureira (2014), não há uma explicação lógica para que os textos sobre estudos de viabilidade de projetos omitam completamente a análise da viabilidade técnica, parecendo ser esta implícita e automática. Entretanto, não é possível conceber um projeto viável economicamente sem que seja tecnicamente viável.

Num modelo organizado de gerenciamento de projetos, o estudo da viabilidade é a fase inicial do planejamento do projeto, na qual objetivos técnicos, econômicos e financeiros serão estabelecidos pela empresa.

De acordo com o Manual para Licenciamento de Projetos de Construção do PMCMV, da Secretaria Municipal de Urbanismo (SMU) da Prefeitura da Cidade do Rio de Janeiro (PCRJ), revisado em 2018, que visa otimizar o tempo total de legalização destes empreendimentos, deve-se atentar à legislação geral e específica necessária para elaboração dos projetos. Para que sejam considerados viáveis, é preciso consultar 
as informações na página da SMU no site da PCRJ, que disponibiliza, entre outros, um sistema de busca de legislação, onde é gerado um documento denominado Relatório de Informações Urbanísticas, que traz os índices básicos para uso e ocupação do solo, entre outros, por exemplo: índice de aproveitamento do terreno, taxa de ocupação, taxa de permeabilidade, altura máxima e gabarito máximo permitido.

\subsection{Código de licenciamento e fiscalização de obras públicas e privadas}

Compondo a base para a produção deste artigo, temo o CLF - Código de Licenciamento e Fiscalização de Obras Públicas e Privadas - que tem como finalidade normatizar e licenciar a execução de toda obra de construção, reconstrução total ou parcial, modificação, modificação de uso, acréscimo, reforma e conserto de edificações em geral, marquises e muros, contenção do solo, canalização e drenagem. Dos pontos abordados no Código de licenciamento e Fiscalização de Obras Públicas e Privadas, os mais relevantes ao assunto do decorrido texto são: a simplificação dos procedimentos de licenciamento sem trazer prejuízo à segurança das edificações, adequar a diversidade de procedimentos decorrente das especificidades de cada tipo de licenciamento e atualizar os procedimentos relativos à fiscalização.

\subsection{Formalização do processo de licenciamento}

No que tange à formalização do Processo de Licenciamento, é necessário que a empresa responsável pelo empreendimento apresente uma série de documentos que são essenciais para a execução da obra. Confere na lista desses documentos o Requerimento online no site da Prefeitura do Rio de Janeiro, e quando houver inscrição imobiliária, também a incluir junto ao requerimento.

O Comprovante de pagamento do DARM-RIO (Documento de Arrecadação Municipal) referente a $50 \%$ da taxa da licença faz parte da lista de documentos exigidos para a efetivação do serviço. A emissão de DARM e da licença de obra só podem ser feitas através do site eletrônico. $O$ projeto de arquitetura em uma via, ficha de enquadramento na SMH (Imóveis na AP5), RGI e/ou PAL, também são exigidos.

Prosseguindo a lista de documentos necessários, temos a Declaração do empreendedor, de que o empreendimento está incluído em programa vinculado à política habitacional municipal, estadual ou federal, informando o valor de venda do imóvel e a 
faixa de renda a ser atendida. Assim também a Planta indicativa com os equipamentos públicos de saúde, educação e transporte público existentes num raio de 1.000 (um mil) metros, também em formato digital; Documentação dos profissionais responsáveis pela execução da obra, no caso o CREA ou CAU; e por fim a documentação do proprietário e/ ou procurador do empreendimento.

\subsection{Documentação para requisição à obra}

Seguindo para a próxima etapa no que diz respeito às documentações para o empreendimento, temos os que se dão para a licença, os quais: Projeto visado pela GEO RIO, no que tange a encostas e áreas suscetíveis, Projeto visado pelo Rio Águas (demarcação de Faixa Non Aedificandi (FNA) e de Drenagem (greide e galerias), Projeto visado pela Zona Oeste Mais Saneamento (Caso o empreendimento esteja situado na Área de Planejamento 5 (AP5), que corresponde a $48 \%$ de todo o território municipal do Rio de Janeiro), caso contrário o projeto será visado pela Companhia Estadual de Água e Esgoto (CEDAE), Termo de investidura (F/SPA), Licença de demolição e Levantamento topográfico, os quais são de extrema importância para o andamento do projeto. $E$ ainda quando o empreendimento estiver em área de ambiência histórica, deverá ter o Projeto visado pelo órgão de tutela, Instituto Rio Patrimônio da Humanidade (IRPH) de competência Municipal, Instituto Estadual do Patrimônio Cultural (INEPAC) de competência Estadual, ou Instituto do Patrimônio Histórico e Artístico Nacional (IPHAN) de competência Federal.

Conforme o Decreto no 32.555/2010, permite que o projeto do dispositivo de tratamento de esgoto dos empreendimentos localizados na AP-5 e licenciados com os benefícios da LC no 97/2009 e sua respectiva aceitação pela Rio-Águas sejam apresentados até a concessão do habite-se.

\subsection{Documentação durante a obra}

Assim como é necessário apresentar documentações para iniciar a obra, há documentos que devem ser obtidos durante a obra por parte do empreendedor, são eles: Declaração da Possibilidade de Abastecimento (DPA) e Declaração de Possibilidade de Esgotamento Sanitário - DPE conforme o Decreto 10.082/1991, Licença Municipal Prévia (LMP) , concedida na fase preliminar do planejamento do empreendimento ou atividade 
aprovando sua localização e concepção, atestando a viabilidade ambiental, conforme Decreto 28.329/2007 que trata do estudo de impacto ambiental e estabelecendo os requisitos básicos e condicionantes a serem atendidos nas próximas fases de sua implementação e emitida pela Secretaria Municipal de Conservação e Mio Ambiente (SECONSERVA), Parecer e projeto visado pela Companhia de Engenharia de Tráfego do RJ (CET RIO), Licença de demolição, Licença das obras de urbanização de logradouro e via interna, comprovação de doação de Lote de equipamento urbano e a Aprovação do Projeto de Remembramento, Desmembramento ou Loteamento (PAL).

\subsection{Aprovação do projeto arquitetônico}

O serviço de aprovação de projeto arquitetônico tem como objetivo principal verificar a adequação da área física às atividades desenvolvidas, seja nos casos de nova obra, reforma, adequação ou ampliação. É necessário a contratação de um Engenheiro Civil ou de um Arquiteto, para que este elabore e assuma a responsabilidade dos projetos e da execução da obra.

A Secretaria Municipal de Infraestrutura e Habitação (SMUIH) é responsável pela aprovação do projeto arquitetônico. Os projetos deverão ser apresentados em um jogo de cópias contendo no mínimo planta de situação, plantas baixas de todos os pavimentos, inclusive do telhado, dois cortes e fachada e deverão estar de acordo com ABNT NBR 13531: 1995 (Elaboração de projetos de edificações) que aborda a confecção dos projetos arquitetônicos, regulando as condições exigidas para a construção de edificações, além de detalhar quais as informações de referência devem constar do projeto.

Após aprovação do projeto de arquitetura, o mesmo deverá ser retirado na SMUIH. A licença e o projeto aprovado deverão ser mantidos sempre no local da obra.

\subsection{Identificação da obra}

Toda obra ou reforma deve ser identificada por uma placa, conforme o Decreto no 36180 DE 30/08/2012 que dispõe sobre a obrigatoriedade de afixação de placa de identificação nas obras realizadas no Município do Rio de Janeiro, que precisa ter, no mínimo, 1,00 metro de altura, os nomes e os respectivos números de classe e função do responsável pela obra, bem como o nome do responsável pelo projeto. Deve conter, também, o endereço completo, o número do processo de licença de obra, o nome 
completo do proprietário e o tipo de obra que será realizada. A confecção da placa (Figura 1) é de responsabilidade do profissional responsável pelo serviço.

Figura 1 - Modelo de Placa de Obra - Decreto no 36.180 de 2012

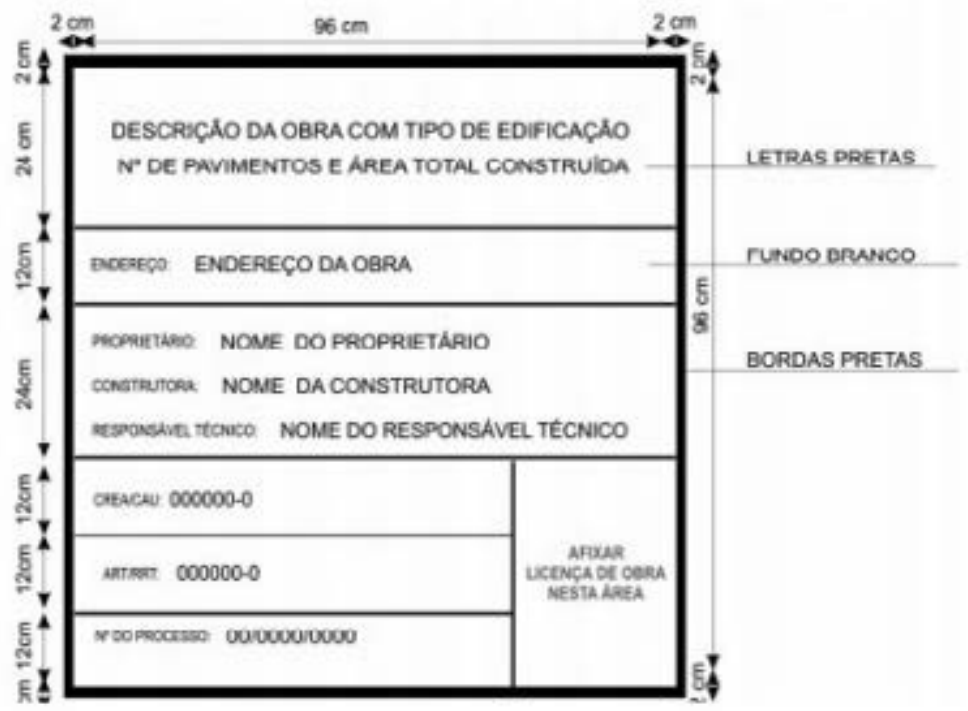

Fonte: (Prefeitura da Cidade do Rio de Janeiro, 2018).

É possível, ainda, que a obra tenha outra placa, em geral, maior ou com o logotipo do executante. Neste caso, porém, a obra deverá ter duas placas, já que uma delas precisa necessariamente obedecer às normas contidas na lei. A placa deverá ser fixada assim que a licença de obra for emitida.

\section{TÉRMINO DE OBRA, HABITE-SE E REGISTRO DE IMÓVEL e CND}

\subsection{Habite-se}

Quando as obras estiverem concluídas é necessário dar ciência aos órgãos públicos. Deverá ser solicitada a vistoria para a concessão do certificado de Habite-se. Para tanto, é preciso comprovar que os trâmites legais foram devidamente cumpridos. 0 habite-se, no entanto, não é a etapa final do processo, já que o registro do imóvel pode ser considerado, hoje, uma das fases mais importante de todo o procedimento da obra e exigido por muitos bancos nos casos de alienação e financiamento para compra.

Após a concessão do habite-se/aceitação, será fornecida uma certidão que possibilitará o registro do imóvel junto ao Registro Geral de Imóveis (RGI) e/ou à 
Secretaria Municipal de Fazenda.

\subsection{Averbação do imóvel}

Para as obras que já possuam o habite-se, é essencial efetivar a averbação do imóvel junto ao RGI, já que muitas operações bancárias, como alienações e financiamentos dependem desse registro. O processo de averbação é feito no cartório de imóveis referente a região que pertence o lote e cada cartório elenca os documentos necessários à averbação. De um modo geral o pedido é feito apresentando o documento de habitese e a certidão negativa de débito (CND). É preciso que o proprietário/construtora entre em contato com o cartório correspondente para averiguação de outros documentos necessários. O pedido de CND é feito conforme o item 3.3.

\subsection{CND - Certidão Negativa de Débito}

É o documento que comprova que a pessoa, física ou jurídica, está em dia com o pagamento de qualquer tributo federal, ou seja, que não há débitos em seu nome. A legislação atual não exige a expedição da CND para procedimentos da obra como, por exemplo, o habite-se. No entanto, a certidão é necessária para que o proprietário/ construtora possa realizar a averbação do seu imóvel junto ao RGI, etapa essa que ocorrerá após a expedição do habite-se. Ao final da obra, o(a) proprietário/construtora são corresponsáveis pela comprovação do pagamento das obrigações previdenciárias dos empregados. O procedimento para a obtenção da CND tem início no Ministério da Fazenda e pode ser feito pela internet, mas é preciso que os construtores tenham uma matrícula CEI - Cadastro Específico do INSS desde o início da obra. Essa matricula servirá para que profissionais liberais possam receber da previdência.

Com o cadastro do CEI realizado, deve-se preencher o formulário DISO Declaração e Informação sobre Obra de Construção Civil, no domínio da Secretaria de Fazenda, com os dados da obra. Com o envio do formulário e, caso não exista divergência de informações, o sistema vai gerar a guia para pagamento da contribuição do INSS. Caso exista alguma divergência entre o que já foi pago durante a obra e o cobrado deve-se realizar o pagamento da diferença, é preciso agendar uma visita à Fazenda para apresentar o habite-se ou o alvará da obra. Qualquer outro documento que for solicitado terá que ser apresentado nesse momento. Se tudo estiver em ordem, a certidão negativa 
de débito será emitida.

\subsection{Fluxograma do processo de legalização}

A figura 2 apresenta de forma resumida as principais etapas de um processo de legalização de um projeto de arquitetura na SMU.

Figura 2 - Fluxograma do processo de legalização

\section{PRINCIPAIS ETAPAS DE UM PROCESSO DE LEGALIZAÇĀO DE UM PROJETO DE ARQUITETURA NA SMURJ}

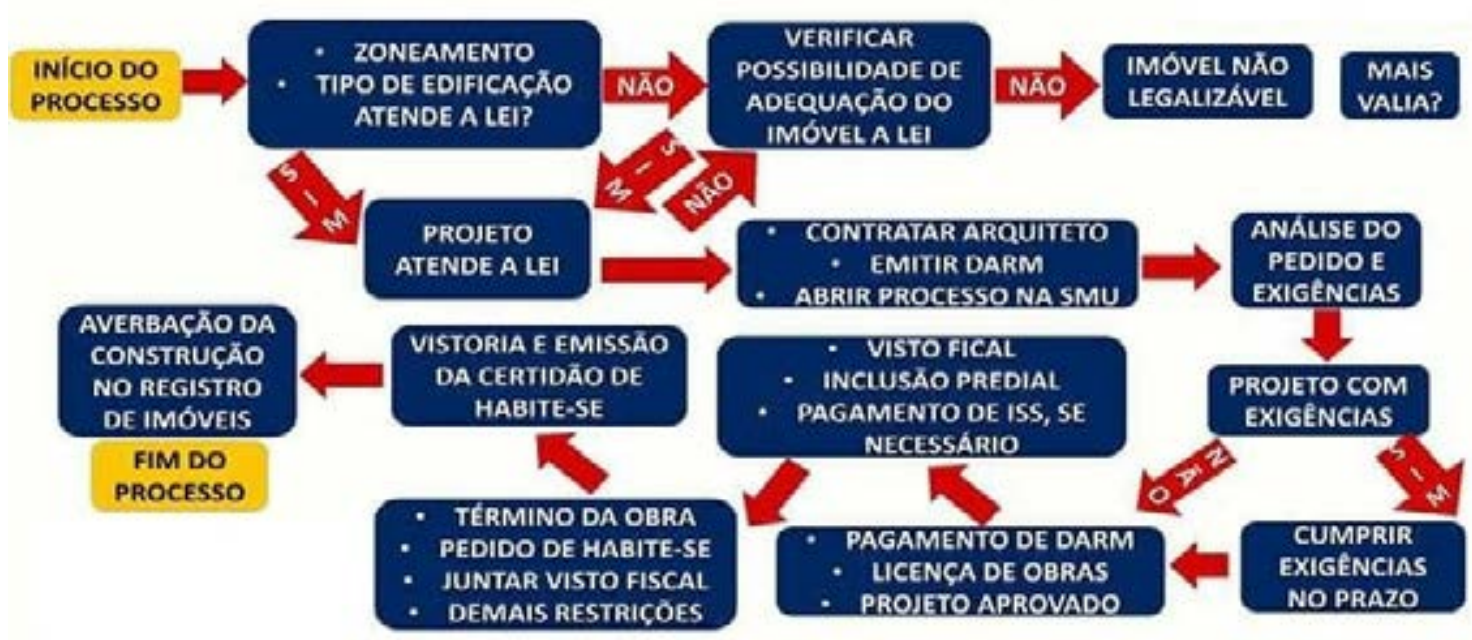

Fonte: (O próprio autor, 2018)

\section{CONCLUSÃO}

O PMCMV conseguiu em poucos anos diminuir o déficit habitacional no Brasil, tendo aumentado consideravelmente a oferta de empreendimentos habitacionais a uma parte da população, que até então se encontrava fora do mercado imobiliário, seja por questões ligadas à renda, ou pela falta de unidades mais adequadas a este público.

Sem sombra de dúvida, um dos entraves a ser perseguido é a velocidade na aprovação dos projetos e obtenção das licenças pelos órgãos e concessionárias de serviços públicos envolvidos, dado que o custo e a demora de tais aprovações, podem inviabilizar o empreendimento.

O objetivo do trabalho foi alcançado, dado que foram demonstradas as etapas relevantes ao processo de licenciamento e acompanhamento das condicionantes para 
licença e aceitação das obras dos empreendimentos em estudo.

Os documentos apresentados contribuem para a análise de problemas que possam surgir, e resposta rápida a mudanças de normas e estrutura pública envolvida, que por vezes sempre ocorrem em novas legislaturas e no Poder Executivo.

O trabalho apresenta ao meio acadêmico um aspecto prático do estudo de projetos arquitetônicos e abre o cenário para novos estudos e propostas que visem otimizar todo o processo de licenciamento.

Uma proposta que pode ser colocada em prática seria a elaboração de cadastro com georefenciamento dos empreendimentos realizados, de modo a se analisar as alterações urbanas e sociais ocorridas numa determinada localidade, apresentando os benefícios e problemas surgidos.

\section{REFERÊNCIAS}

ASSOCIAÇÃO BRASILEIRA DE NORMAS TÉCNICAS. ABNT NBR 13531, 1995 - Elaboração de projetos de edificações. Disponível em <www.abnt.org.br $>$. Acesso em 15 de outubro de 2018.

CEDAE, 2018. Procedimentos para solicitação de DPE e DPA. Disponível em: <www. cedae.com.br>. Acesso em 15 de outubro de 2018.

Decreto no 10.082/1991 - Possibilidade de esgotamento sanitário. Disponível em: <leismunicipais.com.br>. Acesso em 15 de outubro de 2018.

Decreto $\mathrm{n}$ - 19.828/01 - Visa ampliar as condições favoráveis de moradias à população de baixa renda, em áreas urbanas já dotadas de infra-estrutura básica de serviços públicos. Disponível em <http://www.rio.rj.gov.br/dlstatic/10112/136031/DLFE-3162. pdf/dec_19828_01.pdf>. Acesso em 15 de outubro de 2018.

Decreto no 28.329/2007 - Estudo de impacto ambiental. Disponível em: <leismunicipais. com.br>. Acesso em 15 de outubro de 2018. 
de esgoto dos empreendimentos localizados na AP-5 e licenciados com os benefícios da LC no 97/2009 e sua respectiva aceitação pela Rio-Águas sejam apresentados até a concessão do habite-se. Disponível em: <leismunicipais.com.br>. Acesso em 15 de outubro de 2018.

IBGE, 2018. Estimativas populacionais dos municípios. Disponível em: <www. agenciadenoticias.ibge.gov.br/agencia-sala-de-imprensa/2013-agencia-de-noticias/ releases/16131-ibge-divulga-as-estimativas-populacionais-dos-municipios-para-2017>. Acesso em 15 de outubro de 2018.

LEGISLAÇÃO WEB, 2018. Decreto № 36180 DE 30/08/2012. Disponível em: <www. legisweb.com.br>. Acesso em 15 de outubro de 2018.

Lei Complementar no 97/2009 - Normas relativas a edificações e grupamentos de edificações aplicáveis a empreendimentos de interesse social vinculado à política habitacional municipal, estadual e federal. Disponível em <leismunicipais.com.br>. Acesso em 12 de novembro de 2018.

MADUREIRA, OMAR MOORE DE. A viabilidade de projetos em dez lições. Disponível em: <vanzolini.org.br/weblog/2014/10/16/a-viabilidade-de-projetos-em-dez-licoes/>. Acesso em 12 de novembro de 2018.

PREFEITURA DA CIDADE DO RIO DE JANEIRO, 2018. Licenciamento de Obras. Disponível em: <www.rio.rj.gov.br>. Acesso em 15 de outubro de 2018.

.Empreendimentos habitacionais de interesse social. Disponível em:<www2.rio.rj.gov.br>. Acesso em 15 de outubro de 2018.

SECRETARIA MUNICIPAL DA FAZENDA, 2018. ISS, IPTU E TAXAS. Disponível em:<www. rio.rj.gov.br/web/smf>. Acesso em 15 de outubro de 2018.

SECRETARIA MUNICIPAL DE URBANISMO, 2018. Código de Licenciamento e FiscalizaçãoCLF (Projeto de Lei Complementar no 32/2013). Disponível em:<www.rio.rj.gov.br/web. smu>. Acesso em 15 de outubro de 2018. 

www.rio.rj.gov.br/web/smu/licenciamento> Acesso em 15 de outubro de 2018.

. Manual para licenciamento de projetos de construção do Programa Minha Casa Minha Vida. Disponível em: <www.rio.rj.gov.br> Acesso em 12 de novembro de 2018.

ZONA OESTE MAIS SANEAMENTO. Procedimentos para solicitação de DPE e DPA - ZONA AP5. Disponível em: <www.zonaoestemais.com.br>. Acesso em 15 de outubro de 2018. 